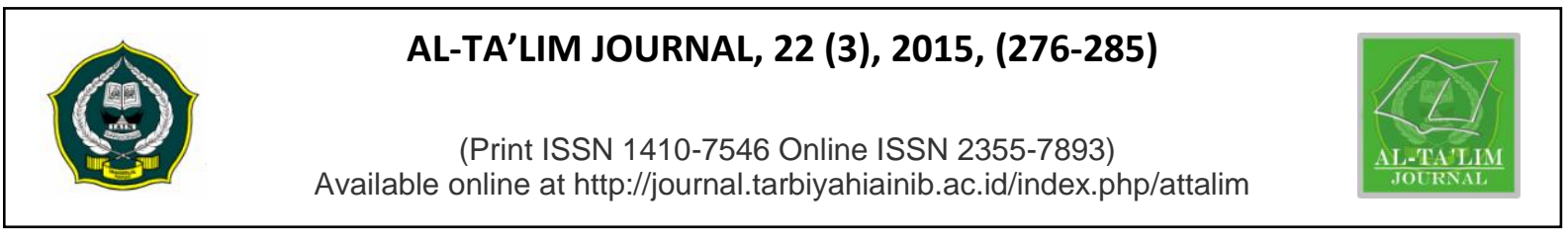

\title{
The Implementation of Technology Approaches to Develop Learners' Autonomy in Learning English
}

\author{
Meylina Muchlis \\ STMIK-AMIK Jayanusa Padang, West Sumatra, Indonesia \\ E-mail : Meylin1983@gmail.com
}

Received: 21th July 2015; Revised: 18th Oktober 2015; Accepted: $10^{\text {th }}$ November 2015

\begin{abstract}
Autonomy in learning is about people taking more control over their learning in the classrooms, the purpose of learn languages and the ways in which they learn them. In this way, technology helps much in learning a language. This paper explores the autonomy as more than preference or strategy by the learner; it must be supported in a systematic way by the teacher and the curriculum for the learner to benefit. The characteristics of successful autonomous learner are explained followed by some examples that shown that learners have in common are that their attitudes were developed after they made their own decision for themselves that exclusively studying in the classroom environment was not enough. The paper also emphasis on technology approaches in developing learner autonomy, especially by using the computer and the internet. Newer technology, particularly the latest online systems, however, allows sound, movement, interactivity (for exercises, demonstrations, online discussion, etc), and the incorporation of genuine material for learning.
\end{abstract}

Keywords: Learner autonomy, technology-based approaches, computer, internet

How to Cite: Muchlis, M. (2015). The Implementation of Technology Approaches to Develop Learners' Autonomy in Learning English. Al-Ta Lim, 22(3). doi:http://dx.doi.org/10.15548/jt.v22i3.144

Permalink/DOI: $\underline{\text { http://dx.doi.org/10.15548/jt.v22i3.144 }}$

\section{INTRODUCTION}

As agent of their own success, a nonnative speaker's English learner needs more effort in order to reach the goal of learning. Diaz-Rico (2008:106) suggests "in Second Language Acquisition (SLA), the need of autonomy is especially important, yet especially difficult to attain". Commonly, teacher does not have enough time to sit around and guide the students all the time, especially after school. In counterbalancing the limitation time of the classroom meeting, Harmer (2003:335) suggests that "students need to develop their own learning strategies, as far as possible they become autonomous learner." Furthermore, Diaz-Rico (2008:109) argues that "autonomy enable students to feel pride in their own achievement." Little (2003) points out more precisely that the practice of learner autonomy, in selfmanagement and interaction with others, requires insight, a positive attitude, a capacity for reflection, and a readiness to be proactive. When students realize that the success of learning depends as much on themselves as on teachers, they begin to have learner autonomy, not waiting to be told what to do. It is obvious that they have to choose and apply they own learning strategies to lead them to the effective learning management and an autonomous learner. 
Students are required to be active and creative to foster their own learning. Because the capacity for control over learning has various aspects, autonomy may take various forms. Fostering autonomy does not imply to specific approach to practice. Students can practice in many ways as long as it encourages and enables them to take greater control over their learning.

The development of autonomy can be done through some approaches; one of them is technology-based approaches. Now on, much of attention of educational technology falls upon computer and internet. As Benson (2001:134) discussed a number of investigations (e.g. Gardner, 1994; Milton, 1997; Mayes, 1994; Makin, 1994; Lewis et al, 1996) have done deal with the interaction with the technology majority seen to be supportive of autonomy. This paper tries to present the technology approaches to make students actively engage in learning process which can help them to take informed decisions and to be a highly skills learners.

\section{Learner Autonomy}

\section{Learner Autonomy in Learning English}

The concept of autonomy first entered the field of language teaching through the council of Europe's Modern Language Project, established in 1971 (Benson, 2001:8). One of the outcomes of this project called Centre de researches at d'Applications en Langues (CRAPEL) which is found by Yves Chalon,the "father" of learner autonomy. Many definitions have been given to the term. Little (2003) points out more precisely that the practice of the learner autonomy requires insight, the positive attitude, a capacity for reflection, and the readiness to be proactive in selfmanagement and in interaction with others.
According to Benson (2001: 8) autonomy is the ability to take charge to one's own directed learning. It has been seen as natural product of the practice of selfdirected learning, or learning in which the objective, progress, and evaluation of the learning are determined by the learners themselves. Meanwhile, Diaz-Rico (2008) defines learner autonomy as "the learners' feelings that studying is taking place due to their own volition", this autonomy is the basis for self-managed, self-motivated instruction.

Generally, autonomy is related to western culture. Sert (2006) reviewed some research studies conducted in eastern (Asian) in teaching and learning adopted different approaches from those of western cultures. Pedagogical approaches assumed that practice in the East do not generally allow or foster students to take responsibility.

The review reveals that learners of eastern culture were just ready for autonomous language learning and they were appreciated the benefits of autonomous study as much as western students, and they would like to be active and independent similar to European students. It implies that the claims passive classroom behaviors of Asian students should be linked to the educational context that can encourage them to be responsible with their own decision in learning. It seems that the passive did not come from the innate of the students but educational system environment do not support the good atmosphere for autonomy.

The successful implementation of learner autonomy in Indonesia may take longer time, because in teaching, the teacher still dominant in classroom context. But it is not impossible to expect to achieve autonomous language learning. 
Widiati (2008) in her study supports this and states that teacher factors seem to hinder the development of learner autonomy because the teacher themselves have been trained within the same education system, and find it hard to change their habits. DiazRico (2008: 104) provides evidence that such autonomy is more than preference or strategy by the learner; it must be supported in a systematic way by the teacher and the curriculum for the learner to benefit. Teacher autonomy supports the involvement that have direct link with students assimilation of their classroom context and subsequent academic outcomes.

In brief, it can be concluded that fostering autonomy may simply mean helping students to learn languages in ways that are more relevant to their lives. Since the course is to foster learner autonomy, it should keep in mind those specific skills involved in our conception of the term. Autonomy is assumed entails ability, a specific attitude, and special behavior. The autonomous learner displays some ability to direct the course of his/her learning, which implies being able to make decisions concerning course management, organization and content. Besides, a special attitude is expected from autonomous learners, who actively engage in the learning process. In this sense, learning about language can help students take informed decisions and make the most of their learning as highly skilled learners. In practice, autonomy also involves certain behavior on the part of learners. They need to be reflective about their own learning, taking the initiative to explore, find possible solutions and contrast results. Thus, according to researcher's views, learner autonomy is ultimately reflected through a series of skills that we seek to foster in the course.

\section{Benefits of Autonomous Learning English}

The use of virtual words to encourage learning is an attractive option for EFL students. Instead of sharing personal information with strangers, the learner can instead share information about their virtual character that they have created based on their fantasy and interests. This would be great way to built both confidence and networking skills with a foreign language. The senior high school students need to have a command of English to succeed in the academic world.

On the other hand, it is believed that students can benefit from becoming more autonomous, that is, from developing skills to control their learning process and getting involved in learning about language. As Ellis and Sinclair (1989 in Macia et al: 2001) suggest, learners who develop self-directed learning strategies related to initiating this can prove to be very useful for students who need to keep on developing academic and language skills to succeed in academic contexts.

From another point of view, Benson (2003) argues that autonomy will make students taking more control over their lives - individually and collectively. Autonomy in learning is about people taking more control over their learning in classrooms and outside them and autonomy in language learning about people taking more control over the purposes for which they learn languages and the ways in which they learn them.

\section{Characteristics of the Successful Autonomous Learner in Learning English}

There are two general arguments in favor of trying to make learners autonomous. Little (2003) states the two as; first, if they are reflectively engaged with their learning, it is likely to be more efficient and effective, because more personal and focused, than otherwise; in 
particular, what is learned in educational contexts is more likely to serve learners' wider agendas. Second, if learners are proactively committed to their learning, the problem of motivation is by definition solved; although they may not always feel entirely positive about all aspects of their learning, autonomous learners have developed the reflective and attitudinal resources to overcome temporary motivational setbacks.

Nunan (2000) outlines common characteristics for people who successfully and dramatically improved their language skills through learning autonomously. These characteristics and requirements include; a diversity of skills, passion and enjoyment for a particular field, a focused and active approach to learning, and finally, pursuit of learning and success despite high probability of failure and public disapproval (Nunan, 2000). Meanwhile, there are other characteristics states by Little (2003):

\section{Autonomous learners understand the purpose of learning, accept responsibility for their learning, share in the setting of learning goals, take the initiative in planning and executing learning tasks, and regularly review their learning to evaluate its effectiveness.}

There are some examples present the couple success stories of students in Hong kong by Nunan (2000) who took their learning in their own hands and excelled because of it. The first example experienced by Nunan when one student named Josephine once approached Nunan to inform him of the great progress she was making with her English. When Nunan continued himself as a teacher credit for the improvements, Josephine countered that it was not his lesson that resulted her improvements, but her Canadian roommate that create domestic living situation. The second example, Nunan (2000) describes the development of another student by the name of Siu Fun:

She loved English but she
quickly came to realize that
learning English in school
wasn't enough, so she found
opportunities to practice of
English out of class.... Siu
Fun used to hang around the
tourist traps after school (to
interact with foreigners in
English).

These examples shown that learners have in common is that their attitudes were developed after they made their own decision for themselves that exclusively studying in the classroom environment was not enough. It implies that the teacher as the instructor should encourage this to the better understand the attitudes and needs of the students.

\section{Approaches to Develop Learner Autonomy}

\section{The Roles of Technology in Learning English}

Currently, when people hear the word technology, they think about the products like; hand phone, computer, and MP3 players. Technology plays an important role in the education for students and can help them achieve their needs of information.

The word technology origins derived from Greek word technologia. Techne means craft and logia means saying (Smaldino et al, 2007: 4). According to Wikipedia (2006) the definition of technology is "a broad term dealing with the use and knowledge of tools and craft". 
The flexibility and variety that characterized the internet are frequently seen as presenting new opportunities that were not previously available to language students and instructors. Fanany (2005) in her study about autonomous learning agrees that the ability of students to make use of technology without the direct supervision of an instructor offers great potential for the enhancement of autonomous learning and the encouragement of student responsibility for their own mastery. To make the use of the technological potentials, however, new kind of material and different forms of presentation are required. The traditional texts and exercises that work well in the classroom are not always appropriate for presentation online and may also require significant and highly-skilled input from and instructor that is not available when students use computer enhanced programs on their own.

For this reason, as we consider ways in which new technology can be incorporated into language teaching programs to achieve goals for student learning, it is also necessary that we think carefully about teaching materials and how to put them online in the internet.

The availability of new technology, but more important its accessibility to senior high school students who are not technology professionals, is affecting a change in the accepted types of learning material for senior high school use. It is now becoming possible to do things that were not possible in the past, and there is also evidence that student expectations are changing.

While traditional textbooks might contain pictures, graphs, figures, and so forth, they must still be read by students, and there is really no other method for approaching the materials they contain. Newer technology, particularly the latest online systems, however, allows sound, movement, interactivity (for exercises, demonstrations, online discussion, etc), and the incorporation of genuine material such as film clips and recordings from radio or television.

These are important advantages in a pedagogical sense as it has been estimated that adult learners retain about $45 \%$ of what they see and $25 \%$ of what they hear but $70 \%$ of what they see, hear, and do (Coleman, 1991). The presence of technology accessible by students in accordance with their own needs means that attention must be paid to materials presentation in the online environment. The nature of learning in the online environment is inherently different from the traditional classroom setting and the way in which languages have been taught historically.

For this reason, it is not possible to simply move existing materials online without considerable adaptation as students will not use them in the same ways they would in a traditional language teaching setting and may not, in fact, have the same goals and expectations for language study.

\section{Technology-Based Approaches}

However learner autonomy is not absolute and may be manifest in varying degrees. Diaz-Rico (2007: 108) suggests that autonomy can be developed by encouraging students to access learning from themselves by going out on their own, drawing the resources outside the classroom. Furthermore, learner autonomy helps remove the barriers between learning and living. Accordingly, autonomous learners' goals are more personal and relevant to life outside the classroom. Some approaches to the promotion of learner autonomy have been broadly divided into 6 categories by 
Benson (2001: 111). The six broad headings are;

(1) Resource-based approaches, which emphasize independent interaction with learning materials, (2) Technology-based approaches, which emphasize independent interaction with educational technologies, (3) Learner-based approaches, which emphasize the direct production of behavioral and psychological changes in the learner, (4) Classroom-based approaches, which emphasise changes in the relationship between learners and teachers in the classroom, (5) Curriculum-based approaches, which extend the idea of learner control over the planning and evaluation of learning to the curriculum as a whole, and (6) Teacher-based approaches which emphasize the role of the teacher and the teacher education in the practice of fostering autonomy among learners.

In his analysis, Benson concludes that no single approach can be deemed best. It can be assumed that these approaches will overlap and that educators must take into consideration relevant cultural and contextual conditions when undertaking autonomisation. But in this paper, the writer will focus on the technology-based approaches because technology holds significant roles in learning English, especially in developing learner autonomy. Lonergan (1994 as cited in Benson, 2001:117) support this through his words:

For many potential SALC (self-access learning centre) users, access to video and television, to computerassisted learning programs, or to interactive CD-ROM is the personal parts of their learning experience in other disciplines. Not only do they welcome the use of technology, they in fact come to expect it, and questions it absence in the modern curriculum.

It is therefore assumed that learning by using technology is considered as something necessity for the students. Many things in technology can be the media for their autonomous learning such as; video, television, computers (e.g. CALL), and other programs. The technological imperative is in part a matter of learner expectations.

In supporting the Lonergan's argument, Motteram (1997 in Benson, 2001:136) shows the use of technology for the development of learner autonomy has a great relationship that:

There has always been a
perceived relationship
between educational
technology and learner
autonomy. This is taking
educational technology in its
broadest sense and taking
learner autonomy as the
super-ordinate term. This has
become increasingly true for
the computers and self-access.

Educational technology can improve and develop learner autonomy through the sophisticated inside the technology tools.

Even though there may be local constraints due to external factors, all teachers can help their students to develop an active, independent attitude to language learning and language use. As autonomy can be fostered most effectively through a 
combination of approaches (Benson 2001: 177), the first two approaches are inextricably entwined: self-access centers, self-instructional materials and distance learning often rely on CALL (Computer Assisted Language Learning) and CMC (Computer Mediated Communication) via the internet.

Although until now there is little empirical evidence of the potential of new technologies in regard to learner autonomy, it seems that both approaches provide the learners with opportunities to self-direct their own learning. In researcher's opinion, the results of learning outcomes as well as an increased control over learning depend primarily on the teacher's ability to guide his or her students towards a reflective use of all materials and media at their disposal.

The effectiveness of the technologybased approaches has been described by Benson (2001: 140) that the skills associated with autonomy can be developed through varieties technology devices. The development depends on the way in which technology available and kinds of interaction that take place around them. He adds that text manipulation and computer-mediated communication applications offer greater opportunities for the control of learning content and collaboration in other modes of self-access learning. In short, learner may be requiring advance autonomy in order to use new technology effectively.

\section{Computer in Learning English}

Computers are one of the key instructional technologies used in education. Smaldino et al (2007: 125) argue that "the computer has a multitude of roles to play in the curriculum, ranging from tutor to student learning tool". For teacher, the computers help them to collect and process student performance, preparing instructional materials, slide show's presentation, and managing classroom activities. Many programs are available in the computers which can make optimal use to support student learning. The familiar applications and programs in computers are; Microsoft office, dictionary, thesaurus, games, simulations, tutorial, problem-solving programs, and graphic tools.

Computer technology has been incorporates into students experiences. Furthermore, Smaldino et al (2007: 126) states that educating students has shifted from providing information to students to opening doors for them to explore topics and to create meaningful learning experiences for themselves. For example, to practice math skills or to search on line databases, specific software can be selected for individual students.

As information tools, through computers, students begin to work with information that available with the easier and funnier process. Smaldino et al (2007:128) suggest that students can use the tools to gather information and to prepare materials that demonstrate their knowledge and understanding of that information.

Some skills that include as the basic operations of computers can be; writing such papers and assignments, calculating to prepare sets of data collected as part of a project, retrieving information for inquiry and research, instructional device to engage them in the real-world problems, knowledge reinforcement to remember specific steps in completing the task, concept development to gather student ideas into concept webs, and problem solving by analyze, monitor, and evaluate the task (Smaldino et al: 2007).

These operations shown that computer has a big role in learning. Many things can be served by computers. It support 
and extension of learning for all students, they can create multimedia materials to demonstrate their knowledge or to challenge other learners.

The rise of the information age has led to the widespread use of information technology (IT) in practically in all spheres of life, school included, and thereby enabling learners to further enhance and take charge of their own learning. Aliponga (2003) review in the past few years many studies conducted across curricula, both qualitative and quantitative, have found that computers are being used to promote learner autonomy (e.g.: Carr, et al.,1998; Ingvarson \& McDonald, 1997; Marcus, 1995; Volker, 1992). Those studies focus on learnercomputer interaction and the resulting effect, in which the computer is programmed to anticipate the responses of the learner.

\section{d. Internet in Learning English}

For the purpose of attaining the objectives of the course, it can be assumed that the Internet is an appropriate medium and a powerful tool for language learning (see Benson 2001). The course is delivered through an internet which includes e-mail communication, shared spaces (like forums), and lists of electronic documents and course materials. Macia et al (2001) suggest that the Internet is also a provider of resources of which the learner can take great advantage. The Web offers a wide variety of materials for language learners, most of which are highly interactive and especially useful for self-access.

With the use of the internet and computers increasing around the world, it seems obvious that electronic means will provide the learning environment of the future. Especially in developing country, we are able to get online and send emails or instant messaging to more people around the world.

Other forms of communication through internet include discussion boards, interactive blogs, and online forums. In addition, many English students are downloading music, lyrics, movies, and TV shows that allows them to get exposure to different accents and expressions. Other virtual environments can be used to develop language skills while also morphing the task of learning into an enjoyable hobby. Social networks such as; MySpace, Facebook, and multiply have the potential to awareness about language that will drive people at a very young age to become involved in learning language. A learner can present themselves and learns more about others.

Other technological means that can be used to improve language ability are voice-chat programs such iChat and Yahoo messengers programs. These programs allow people to talk to others around the world in the real time and they are free to use while online in anywhere. When initial connection are made through social networks on the internet, users can then use the voice programs to call each other and practice oral skills by applying new language items learn through writing and reading the written chat in the screen.

When reviewed recent literature in an attempt to characterize the facilitative relationship between Internet use for language learning resource, and technologybased approaches to the promotion of learner autonomy. The facilitative nature of the relationship was manifest each of the approaches in a number of important ways.

The Internet is seen as an unparalleled resource bank and intercultural platform that provides greatly expanded opportunities for learning and 
communication independent of time and place. The introduction of an online environment into the classroom was described as causative of a re-evaluation of teacher beliefs leading to a more decentralized approach to teaching, and renegotiated teacher-student interaction. The Internet is also regarded as a forum for learning by the application of learning i.e., by 'doing and thinking'. Effective Internet use stresses the utility of addressing metacognition and learner strategies and promotes evolutionary changes in teaching and learning methodologies. However, the importance of the benefits of Internet use for language learning means that they cannot easily be ignored by teaching professionals and learners who value autonomy, both now and in the future.

\section{CONCLUSION}

Autonomy in learning is a process and not a product that many EFL students seek today. Autonomy requires understanding one's own strengths and weaknesses and accumulating a diverse of resources to maximize exposure and improvements in learning English includes in speaking, listening, reading and writing. Skills can be learnt by studying independently and with other EFL students, but skills are not truly assimilated when they can be confirmed and responded to by a qualified mentor.

Technology benefits the students by encouraging critical thinking when using public means to search learning sources and communicate such as chat sites and internet forums. By using the activities mentioned in this paper, and by becoming more educated about the opportunities of using the technology as broad as possible, an increased interest in independent and formal language learning should ensue.

\section{REFERENCES}

Aliponga, J. (2003). Developing Learner Autonomy Online.Vol.6, No. 1.(http://www.cdtl.nus.edu.sg/brief/V 6n1/sec3.htm, Retrieved on May 28, 2015).

Benson, P. (2001). Teaching and Researching Autonomy in Language Learning. London: Longman.

Benson, P. (2003). Learner autonomy in the classroom.In D. Nunan (Ed.), Practical English teaching (pp. 289305). New York, NY: McGraw Hill.

Coleman, JA. (1991). Interactive Multimedia in Brierley, W and Kemble, IR, eds, Computers as a Tool in Language Teaching, Ellis Horwood, New York, 87-112.

Diaz, Lynne \& Rico. (2008). Strategies for Teaching English Learner. ( $2^{\text {nd }}$ ed.). United State: Pearson Education Inc.

Fanany, K. (2005). Autonomous Learning Through Online Teaching.PacCALL Journal. Vol. 1, No.1, (http://paccall.org/Journal/V-1-1papers/Fanany-AutonomousLearning- Online.pdf, retrieved onMay 2, 2015).

Harmer, Jeremy. (2003). The Practice of English Language Teaching. ( $3^{\text {rd }}$ ed.). Malaysia: Longman.

Little, D. (2003). Learner autonomy and second/foreign language Learning.The Guide to Good Learning and Teaching in Language, Linguistics, and Area Studies(http://www.lang.ltsn.ac.uk/re sources/goodpractice.aspx?resourceid $=1409$, retrieved on June 1, 2015). 
Macia, E.A, Carmen Rueda R, Antonoa Soler C, Claudia Barahona F. (2001). Developing Learner Autonomy through Virtual EAP Course at University.(http://www.publicacions. ub.es/revistes/bells12/PDF/art01.pdf, retrieved onMay 2, 2015).

Nunan, D. (2000). Autonomy in Language Learning.Plenary presented at ASOCOPI 2000, Cartagena, Colombia, October 2000, (http://ec.hku.hk/dcnunan/prese ntations/autonomy_lang_lear.pdf, retrieved onDecember 2, 2014).

Sert, N. (2006). EFL Student Teacher's Learning Autonomy. Volume 8, issue 2, Article 8. (http://www.asian-efljournal.com,retrieved on June 2, 2015).
Smaldino, Deborah L. Lowther, and James D. (2007). Instructional technology and media for Learning $\left(9^{\text {th }}\right.$ ed $)$. Ohio: Pearson Education Inc.

Widiati, U. (2008). Best Practices in English Language Teaching. Paper Presented at National Seminar on Language Literature and Language teaching (NSL3T) Padang, State University of padang, 11-12 October.

Wikipedia. (2006). Technology definition, (http://en.wikipedia.org/wiki/Technol ogy, Retrieved on June 1, 2015). 